\title{
Ranking dos Legislativos Locais na Construção da Accountability: um Estudo a partir dos Portais Eletrônicos de Municípios de Santa Catarina
}

\author{
Ranking of Local Legislative in Accountability Construction: a Study from the Electronics \\ Portals of Santa Catarina's Municipalities
}

\author{
Fabiano Maury Raupp \\ fabianoraupp@ hotmail.com \\ UDESC
}

\author{
José Antonio de Pinho \\ jagp@ufba.br \\ UFBA
}

\begin{abstract}
Resumo: O artigo faz uma análise de 93 portais eletrônicos de câmaras municipais do Estado de Santa Catarina com o objetivo de propor um ranking em termos de construção da accountability, representada, neste estudo, pela construção de condições de prestação de contas, transparência e participação. A pesquisa é descritiva, realizada por meio de um estudo de levantamento, com abordagem predominantemente qualitativa. Na coleta de dados foi utilizado o protocolo de observação, que teve por objetivo verificar nos portais eletrônicos de câmaras municipais a ocorrência dos indicadores de prestação de contas, transparência e participação do modelo de análise. As observações nos portais para identificar os indicadores foram realizadas em dezembro de 2010, e janeiro e fevereiro de 2011. A proposição do ranking baseou-se no grau decrescente de condições de construção das três dimensões analisadas: prestação de contas, transparência e participação. Os resultados da pesquisa empírica mostram, com pouquíssimas exceções (Criciúma, Florianópolis, Joinville, Canoinhas, Chapecó, Rio do Sul, São José, Timbó e Xanxerê), evidências de que os portais eletrônicos não são utilizados como tecnologia de promoção da accountability. O ranking construído evidencia que, de maneira geral, há uma ausência de construção de accountability, visto que os portais eletrônicos de câmaras municipais do Estado de Santa Catarina são, atualmente, instrumentos com nula ou baixa capacidade, servindo, na sua maioria, como murais eletrônicos.
\end{abstract}

Palavras-chave: Legislativo local. Accountability. Portal eletrônico.

Abstract: The article analyzes 93 electronic portals of the City Councils in the State of Santa Catarina so as to propose a ranking in terms of accountability construction, represented in this study by constructing conditions of accountability, transparency and participation. The research is descriptive, conducted through a survey study, with a predominantly qualitative approach. For data collection the observation protocol was used in order to verify in the electronic portals of the city councils the occurrence of accountability, transparency and participation indicators from the analysis model. Portals observations to identify indicators were held in december 2010, and january and february 2011. The proposition of the ranking was based on the decreasing degree of construction conditions of the three analyzed dimensions: accountability, transparency and participation. The results of the empirical research show, with very few exceptions (Criciuma, Florianópolis, Joinville, Canoinhas, Chapecó, Rio do Sul, São José, Timbó e Xanxerê), evidence that the portals are not used as electronic technology to promote accountability. The ranking constructed shows that, in general, there is a lack of accountability construction, since the electronic portals of City 
Councils in the State of Santa Catarina are currently instruments with null or low capacity, serving mostly as electronic murals.

Keywords: Local legislative. Accountability. Electronic portals.

Artigo recebido em: 01.11.2012; Aceito em: 30.01.2013

\section{Introdução}

As possibilidades que a internet oferece para que diversos tipos de serviços estejam ao alcance dos cidadãos são do interesse de todos. Entretanto, para garantir que qualquer cidadão realmente possa ter acesso a essas informações e serviços, é necessário levar em conta diversas questões, como a disponibilidade de infra-estrutura de comunicação e os meios tecnológicos utilizados para a disponibilização dos conteúdos (FREIRE, CASTRO, FORTES, 2009).

Tem-se percebido um crescimento acelerado das tecnologias de informação e comunicação (TICs) nos últimos anos, o que impede medir, por décadas, esse avanço devido à crescente obsolescência existente. A vida tem sido tomada pelas TICs, configurando, inclusive, um possível novo estágio do desenvolvimento das sociedades - a sociedade da informação - que coloca não só enormes possibilidades de mudança social, como uma série de questões marcadas por ambigüidades e indefinições. Ao tempo que se abre um enorme leque de possibilidades, também se coloca um rol, não menor, de preocupações com as novas configurações da sociedade. Todo esse ambiente de novas tecnologias suscita um conjunto de questões para o qual certamente ainda não existem respostas assertivas (PINHO, 2008).

Uma destas questões, levantada no artigo, refere-se à forma como os portais eletrônicos são construídos no tocante à prestação de contas dos gastos incorridos, transparências das ações parlamentares e participação da sociedade nas ações governamentais. Para tanto, o artigo faz uma análise de 93 portais eletrônicos de câmaras municipais do Estado de Santa Catarina com o objetivo de propor um ranking dos portais eletrônicos de municípios catarinenses em termos de construção da accountability, representada, neste estudo, pela construção de condições de prestação de contas, transparência e participação.

Dependendo dos objetivos e da forma com que são implementados, os portais eletrônicos podem contribuir para a construção de accountability. No entanto, necessita-se de pesquisas empíricas que possam mostrar evidências a fim de afirmar ou refutar os portais eletrônicos como tecnologia de promoção de accountability (RAUPP e PINHO, 2012). Direcionado pelo propósito de contribuir com evidências empíricas sobre o uso dos portais eletrônicos, o estudo está organizado em cinco seções, iniciando com esta introdução. Após, fez-se uma incursão teórica sobre o uso das TICs para prestação de contas transparência e participação. Em seguida, são apresentados os procedimentos metodológicos adotados na pesquisa. Posteriormente, expõem-se os resultados alcançados. Por fim, são tecidas as conclusões do estudo.

\section{Uso das TICs para Prestação de Contas, Transparência e Participação}

O quadro teórico do artigo contempla os conceitos de prestação de contas, transparência e participação, considerados dimensões da accountability e discutidos à luz das TICs e do governo eletrônico/legislativo eletrônico. Assim, o termo accountability é utilizado no estudo conforme colocado por Pinho e Sacramento (2009), cujo significado envolve responsabilidade (objetiva e subjetiva), controle, transparência, obrigação de prestação de contas, justificativas 
para as ações que foram ou deixaram de ser empreendidas, premiação e/ou castigo.

Sabe-se que a disseminação das TICs, através de diferenciados instrumentos, tem promovido avanços em diversos setores, como é o caso do setor público, que tem implementado instrumentos com o objetivo de tornar a gestão governamental mais eficiente. $\mathrm{O}$ governo eletrônico é uma dessas iniciativas e tem disponibilizado serviços à sociedade, além de possibilitar uma aproximação entre o cidadão e o ente governamental, contribuindo, em tese, para uma maior democratização dos processos, expressa pela accountability (RAUPP e PINHO, 2011).

Recorremos ao conceito de governo eletrônico, segundo Ruediger (2002), com foco no uso das TICs aplicadas a um amplo arco das funções de governo e, em especial, deste para com a sociedade. Em termos gerais pode-se pensar nas seguintes relações sustentadas pelo governo eletrônico: 1) aplicações web com foco para o segmento governo-negócio (G2B Governmentto Business); 2) aplicações web voltadas para a relação governo-cidadão (G2C Governmentto Costumer); e 3) aplicações web referentes a estratégias governo-governo (G2G - Governmentto Government). Em conjunto, tecnicamente, o governo eletrônico, além de promover essas relações em tempo real e de forma eficiente, poderia ainda ser potencializador de boas práticas de governança e catalisador de uma mudança profunda nas estruturas de governo, proporcionando mais eficiência, transparência e desenvolvimento, além do provimento democrático de informações para decisão.

As TICs têm se espraiado pelo setor governamental por meio do que se chama e-gov ou governo eletrônico, representado pela informatização de suas atividades internas e pela comunicação com o público externo. Uma forma central dessa informatização tem sido a construção de portais governamentais, por intermédio dos quais os governos mostram sua identidade, seus propósitos, prestam contas, possibilitam a concentração e disponibilização de serviços e informações, o que facilita a realização de negócios e o acesso à identificação das necessidades dos cidadãos. Não se esgotam nesses elementos, no entanto, os objetivos dos governos eletrônicos, também incluindo outros referentes ao aumento da transparência e participação da sociedade nas ações governamentais. Esse corpo de objetivos está fundamentado nas características intrínsecas que as novas TICs possuem, que permitem e aceleram a comunicação e a interação entre sociedade e governo (PINHO, 2008).

Para Cardoso (2004), o potencial do governo eletrônico para traduzir, em termos burocráticos e administrativos, a mesma rapidez e eficácia que a internet vem possibilitando nas transações privadas é gigantesco, permitindo: uma revolução na prestação de serviços públicos, tanto pela melhoria dos padrões de prestação de tais serviços como pela significativa redução de seus custos; uma revolução na análise e decisão de processos não repetitivos e que envolvem mais de uma agência ou dependência governamental; reformulação dos métodos pelos quais o Estado compra e contrata bens e serviços; processos de compras e contratações como uma transparência essencial para que exista verdadeiro controle público sobre os atos e dispêndios dos governantes; uma dramática alteração nas formas pelas quais os cidadãos interagem com seus representantes e governantes, seja em termos de transmitir seus desejos, aspirações e necessidades, seja em termos de opinar sobre iniciativas, projetos ou políticas governamentais ou, ainda, em termos de acompanhar e controlar a ação daqueles que os representam e governam.

Diante das potencialidades, temas como desempenho, eficiência, eficácia, transparência, mecanismos de controle, qualidade do gasto público e prestação de contas, relacionados ao processo de modernização da gestão pública, foram associados ao processo de construção de programas de governo eletrônico. O desdobramento desses temas em políticas públicas e iniciativas concretas, explicitadas nos programas de governo, requerem o uso de tecnologia, tornando os programas de governo eletrônico elementos alavancadores de novos patamares de 
eficiência da administração pública (DINIZ et al., 2009). Como consequência, as pressões da sociedade para que o governo otimize seus gastos e atue, cada vez mais, com transparência, qualidade e de modo universal na oferta de serviços aos cidadãos e organizações em geral, motivaram a construção de sistemas baseados na Internet, os quais conformam, na prática, o governo eletrônico (MEDEIROS e GUIMARÃES, 2006).

Os estudos e reflexões sobre o governo eletrônico têm maior recorrência com o poder Executivo. Contudo, o material teórico e empírico pode ser utilizado, também, em pesquisas com o poder legislativo, resguardadas as especificidades de cada poder. No legislativo esse instrumento foi denominado de legislativo eletrônico. Para Zurra e Carvalho (2008), o legislativo eletrônico teria, entre outros objetivos, disponibilizar informações como notícias diárias sobre as ações parlamentares, ordem do dia, relatórios semestrais e anuais sobre as ações desenvolvidas pelos parlamentares e pelas comissões, lista de freqüência dos deputados, execução orçamentária, entre outras informações. Além disso, pode-se também oportunizar um canal de comunicação entre a sociedade e a Casa Legislativa e também com os parlamentares, fato este que facilita o contato com este Poder, considerado ainda por muitos, como distante da população. Devido a esse distanciamento, grande parte da população só pode acompanhar a atuação dos parlamentares, através dos meios de comunicação, entre eles os portais eletrônicos dos legislativos (ZURRA e CARVALHO, 2008).

Em relação à prestação de contas, a publicação da Lei n. ${ }^{\circ}$ 12.527, de 18 de novembro de 2011, conhecida como Lei de Acesso a Informações Públicas, reforça a obrigação dos agentes públicos em utilizar meios eletrônicos na divulgação de informações acerca dos atos praticados na administração pública, incluindo o legislativo, nas diferentes esferas. Algumas das exigências já constam no texto da Lei n..$^{\circ} 101$, de 4 de maio de 2000, conhecida como Lei de Responsabilidade Fiscal, bem como na Lei n. ${ }^{\circ}$ 131, de 27 de maio de 2009, denominada comumente de Lei da Transparência.

Prado (2004) destaca a importância de uma discussão sobre prestação de contas que ultrapasse a perspectiva legal. Para o autor, a utilização de websites na avaliação da disponibilidade de informações sobre as contas públicas pode ser enquadrada em três categorias distintas de análise: Publicização: corresponderia à análise da disponibilidade de informações sobre as contas públicas; Prestação de contas: corresponderia a uma etapa mais avançada de análise, em que além de verificar a disponibilidade de informações sobre as contas públicas, verifica a existência de justificativa, por parte da administração, das contas apresentadas; Responsabilização (accountability): refere-se à análise do ciclo completo da accountability, em que se verifica não só a prestação de contas, mas também a existência de possíveis sanções ou incentivos decorrentes da prestação de contas pela administração.

Prado (2004) entende o ato de prestar contas como uma das etapas da accountability, que implica não só a disponibilidade de informações, mas também a existência de justificativas sobre o desempenho fiscal da administração. A análise do ciclo completo da accountability demandaria verificar a existência de eventuais sanções ou punições relativas à prestação de contas, ou incentivos à permanência no governo de uma administração, decorrentes de uma boa gestão fiscal (PRADO, 2004). Como as publicações geralmente não são suficientes para suscitar o controle social, é preciso que elas estejam ao alcance do maior número possível de pessoas, em termos de entendimento das informações. Devem permitir que qualquer indivíduo, com interesse nas divulgações, seja capaz de assimilar e compreender as informações disponíveis (AGOSTINETO e RAUPP, 2010).

Dado o avanço da tecnologia, percebe-se que o governo eletrônico não deve ser visto apenas por meio da disponibilização de informações que pode configurar a prestação de contas mas, também, pela vasta gama de possibilidades de interação e participação entre governo e sociedade e pelo compromisso de transparência por parte dos governos. Em outras palavras, 
as TICs contêm um enorme potencial democrático, desde que haja definição política no sentido da participação popular e da transparência, pois o governo pode deixar de oferecer o que não quer mostrar, para nem mencionar o que quer esconder (PINHO, 2008).

Neste sentido, outro conceito importante na construção teórica do artigo refere-se à transparência. Considerando que uma das premissas fundamentais da democracia representativa é que ela deva ser o governo do visível e que, por princípio, nada deva permanecer escondido, é fundamental que os governantes tornem públicos não só os próprios atos, mas também disponibilizem informações relativas à administração pública, de forma a tornar o governo cada vez mais transparente. Pressupõe-se que a criação de um programa de governo eletrônico pode dotar de maior transparência a administração pública, e que esta transparência, por extensão, pode melhorar a accountability dos governos. (PRADO, LOUREIRO, 2006).

Para Gomes Filho (2005), a transparência pública não se confunde com publicidade, que fundamenta o moderno Estado de direito. As duas noções são distintas, ainda que a publicidade garanta ao poder público certa transparência. A diferença é a exigência da publicidade é atendida com a publicação dos atos do poder público no veículo oficial de imprensa, ao passo que a transparência não se satisfaz com o mero cumprimento de formalidades. Ela é mais exigente. Não pode ser vista, mas pode ser percebida em uma determinada atitude comportamental que se manifesta no relacionamento com o outro. É transparente quem remove barreiras ao conhecimento de si pelo outro. Portanto, requer a disposição, o destemor de desproteger-se em relação ao outro, de expor-se, de mostrar-se como se é, de dar a conhecer externamente aquilo que não é aparente e que de outro modo não seria do conhecimento do outro (GOMES FILHO, 2005).

Segundo Platt Neto et al. (2007), a transparência contempla três elementos ou dimensões. O primeiro elemento é a publicidade. Por publicidade, entende-se a ampla divulgação de informações à população, propiciando-se o acesso em múltiplos meios de baixo custo e domínio dos usuários. Pressupõe-se, ainda, a oportunidade das informações fornecidas, com tempestividade e em tempo hábil ao apoio às decisões. O segundo elemento da transparência, conforme os autores, é a compreensibilidade das informações. Essa dimensão relaciona-se à apresentação visual, incluindo a formatação das informações (demonstrativos, relatórios etc), e ao uso da linguagem.Busca-se idealmente a simplicidade, a linguagem acessível e orientada ao perfil dos usuários, no sentido de aumentar o entendimento das informações. O terceiro elemento da transparência das contas públicas é a utilidade para decisões. A utilidade está fundamentada na relevância das informações. A relevância, por sua vez, pode ou não coincidir com os interesses dos usuários. Associada à relevância, está a confiabilidade das informações a que os usuários têm acesso, ou seja, a garantia de veracidade do que é divulgado. A comparabilidade deve ser propiciada entre período se entre entidades.

Tomando por base pesquisas já realizadas no Brasil e no exterior, que tinham por objetivo investigar ou, de alguma forma, avaliar a divulgação de informações concernentes à gestão pública em diferentes níveis governamentais que pudessem consubstanciar práticas de transparência, Cruz, Silva e Santos (2009), constataram que há um nível de divulgação notadamente abaixo dos requisitos mínimos de divulgação propostos nos modelos e nos códigos de boa governança no setor público. Esse baixo nível de divulgação de informações sobre a gestão pública se verifica até mesmo quando se trata de informações cuja disponibilização é exigida por lei.

Para Cruz, Silva e Santos (2009), a assimetria informacional existe porque há informações que os gestores públicos optam por não divulgar, em decorrência de interesses que possuem que são conflitantes com os interesses coletivos dos cidadãos. Além disso, as informações são 
divulgadas nas quantidades, formas e períodos estratégicos, que favoreçam a permanência dos gestores e assegurem a realização dos seus interesses.

Um último conceito deste artigo, intimamente ligado ao anterior, é a questão da participação. Para Teixeira (1997), a participação requer a existência de mecanismos próprios, sejam institucionais ou não. Os institucionais podem dar-lhe um caráter de permanência e regularidade, mas também, contêm o risco de submeter os agentes sociais à lógica própria do poder, à racionalidade técnico-burocrática. Existem outros mecanismos peculiares aos movimentos sociais que podem garantir sua autonomia e potencializar sua ação frente ao Estado, à sociedade política, ao mercado. Destaca ainda o autor que a participação utiliza-se não apenas de mecanismos institucionais já disponíveis ou a serem criados, mas os articula com outros mecanismos e canais que se legitimam pelo processo social. Não nega o sistema de representação, mas busca aperfeiçoá-lo, exigindo a responsabilização política e jurídica dos mandatários, o controle social e transparência das decisões, prestação de contas, tornando mais frequentes e eficazes certos instrumentos de participação semidireta (plebiscito, referendo, iniciativa popular de projeto de lei, democratização dos partidos).

Com o potencial de interatividade e compartilhamento em rede, os governos procuram disponibilizar para os cidadãos condições diversas para o acesso às informações governamentais, visando a resolver (em tese) o déficit de participação política dos indivíduos - importante iniciativa para a consolidação do processo democrático (SANTOS e SILVA, 2011). Para Rezende (2007), a participação dos munícipes na condução do município é uma necessidade inexorável. Uma das formas para contribuir nesse desafio é o planejamento estratégico trabalhado de forma coletiva, onde as informações sistematizadas são prérequisitos para as atividades de organização das prefeituras e dos municípios (REZENDE, 2007).

Há razoável concordância nas possibilidades de aumento de participação do cidadão pelo uso dos meios digitais. Mesmo aqueles que defendem uma imagem social na qual as formas de dominação e poder estão sendo potencializadas pela tecnologia de informação, acreditam que esse não é o destino inexorável da sociedade, podendo os meios de computação e comunicação serem utilizados para a ampliação da democracia (CUNHA e SANTOS, 2005). Assim, seria contraproducente desconsiderar a importância das políticas de inclusão digital, pois estas se revelam fundamentais para a participação política, ampliando o acesso a conteúdos informacionais digitais às camadas sociais menos favorecidas. Assim, compete ao governo e representantes políticos atentarem para o potencial informacional da internet, com iniciativas que promovam de fato interconexões com os cidadãos, fomentando as políticas de inclusão sócio-digital, a participação e a discussão política (SANTOS e SILVA, 2011).

\section{Procedimentos Metodológicos}

A análise de 93 portais eletrônicos de câmaras municipais do Estado de Santa Catarina com o objetivo de propor um ranking de câmaras municipais em termos de construção da accountability é resultado de uma pesquisa descritiva, realizada por meio de um estudo de levantamento, com abordagem predominantemente qualitativa. A coleta de dados foi realizada utilizando como instrumento o protocolo de observação que, segundo Creswell (2007), é utilizado para registrar dados de observações múltiplas durante a realização de um estudo qualitativo.

O objetivo do protocolo de observação foi verificar nos portais eletrônicos de câmaras municipais a ocorrência dos indicadores de prestação de contas, transparência e participação do modelo de análise proposto por Raupp e Pinho (2012). As observações nos portais para identificar os indicadores de prestação de contas, transparência e participação nos portais

R. Cont. Ufba, Salvador-Ba, v. 7, n. 1, p. 69-83, Janeiro-abril 2013 
foram realizadas em dezembro de 2010, e janeiro e fevereiro de 2011. O modelo de análise utilizado no estudo é apresentado por meio da figura 1.

\begin{tabular}{|c|c|}
\hline \multicolumn{2}{|r|}{ Prestação de Contas } \\
\hline Capacidade & Indicadores \\
\hline Nula & Inexistência de qualquer tipo de Relatório e/ou impossibilidade de sua localização \\
\hline Baixa & $\begin{array}{l}\text { Divulgação parcial e/ou após o prazo do conjunto de Relatórios Legais dos gastos } \\
\text { incorridos }\end{array}$ \\
\hline Média & Divulgação do conjunto de Relatórios Legais dos gastos incorridos no prazo \\
\hline Alta & $\begin{array}{l}\text { Divulgação, além do conjunto de Relatórios Legais no prazo, de Relatórios } \\
\text { complementares dos gastos incorridos }\end{array}$ \\
\hline \multicolumn{2}{|r|}{ Transparência } \\
\hline Capacidade & Indicadores \\
\hline Nula & Inexistência de qualquer tipo de indicador de transparência \\
\hline \multirow{3}{*}{ Baixa } & Detalhamento das seções (ordem do dia, atas das seções) \\
\hline & Notícias da câmara municipal sobre as atividades dos vereadores \\
\hline & Disponibilização da legislação \\
\hline \multirow{2}{*}{ Média } & Disponibilização de legislação com possibilidade de download \\
\hline & Vídeos das sessões legislativas \\
\hline \multirow{4}{*}{ Alta } & Divulgação das matérias nas fases de tramitação \\
\hline & Vídeos das sessões legislativas ao vivo \\
\hline & TV Câmara \\
\hline & Rádio Câmara \\
\hline \multicolumn{2}{|r|}{ Participação } \\
\hline Capacidade & Indicadores \\
\hline Nula & Inexistência de qualquer tipo de canal para a participação dos cidadãos \\
\hline \multirow{4}{*}{ Baixa } & E-mail da câmara \\
\hline & E-mail de setores da câmara \\
\hline & E-mail do vereador \\
\hline & Formulário eletrônico \\
\hline \multirow{4}{*}{ Média } & Home page do vereador \\
\hline & Twitter \\
\hline & Vídeo YouTube \\
\hline & Monitoramento das ações dos usuários \\
\hline \multirow{2}{*}{ Alta } & Ouvidoria \\
\hline & Indicativo de retorno \\
\hline
\end{tabular}

Figura 1 - Modelo de análise

Fonte: Raupp e Pinho (2012).

Segundo Raupp e Pinho (2012), em relação à prestação de contas, será considerado com nula capacidade o portal no qual for observada a inexistência de qualquer tipo de Relatório e/ou impossibilidade de sua localização. Caso haja uma divulgação parcial e/ou após o prazo do conjunto de Relatórios Legais dos gastos incorridos, o portal eletrônico apresenta baixa capacidade em prestar contas. A média capacidade do portal será indicada a partir da divulgação do conjunto de Relatórios Legais dos gastos incorridos no prazo. A alta capacidade do portal será identificada se houver divulgação, além do conjunto de Relatórios Legais no prazo, de Relatórios complementares dos gastos incorridos.

No tocante à transparência, Raupp e Pinho (2012), propõem que o portal terá capacidade nula no caso de inexistência de qualquer tipo de indicador de publicização das atividades dos vereadores. A baixa capacidade será definida pela presença de pelo menos um dos seguintes indicadores: detalhamento das seções (ordem do dia, atas das seções); notícias da câmara municipal sobre as atividades dos vereadores; disponibilização da legislação. Já a média capacidade será identificada nos portais que apresentarem, de forma cumulativa, pelo menos um dos indicadores de baixa capacidade e um dos seguintes indicadores: disponibilização de 
legislação com possibilidade de download, vídeos das sessões legislativas. A alta capacidade será identificada caso o portal apresente, de forma cumulativa, pelo menos um dos indicadores de baixa capacidade, pelo menos um dos indicadores de média capacidade e um dos seguintes indicadores: divulgação das matérias nas fases de tramitação; vídeos das sessões legislativas ao vivo; TV Câmara; Rádio Câmara.

No que concerne à participação, Raupp e Pinho (2012) entendem que será considerado com nula capacidade o portal no qual for observada a inexistência de qualquer tipo de canal para a participação dos cidadãos. Abaixa capacidade será identificada caso o portal apresente pelo menos um dos seguintes indicadores: E-mail da câmara; E-mail de setores da câmara; E-mail do vereador; Formulário eletrônico. Será considerado com média capacidade o portal que apresentar, de forma cumulativa, pelos menos um dos indicadores de baixa capacidade e um dos seguintes indicadores: Home page do vereador; Twitter; Vídeo YouTube; Monitoramento das ações dos usuários. Para que o portal tenha alta capacidade, deverá apresentar, de forma cumulativa, pelos menos um dos indicadores de baixa capacidade, pelo menos um dos indicadores de média capacidade e um dos seguintes indicadores: ouvidoria; indicativo de retorno.

\section{Resultados}

Santa Catarina localiza-se na região Sul do Brasil, tendo como Estados limítrofes Paraná e Rio Grande do Sul. É um Estado formado por 293 municípios, distribuídos em 6 mesorregiões: Grande Florianópolis, Norte Catarinense, Oeste Catarinense, Serrana, Sul Catarinense e Vale do Itajaí (IBGE, 2010). A população do Estado e a quantidade de municípios por grupos populacionais são apresentados na tabela 1.

Tabela 1 - Municípios por classe populacional

\begin{tabular}{|l|c|r|}
\hline \multicolumn{1}{|c|}{ Classe Populacional } & Quantidade de municípios & População nos municípios \\
\hline Até 5.000 habitantes & 108 & 341.260 \\
\hline De 5.001 a 10.000 habitantes & 64 & 467.560 \\
\hline De 10.001 a 20.000 habitantes & 60 & 819.028 \\
\hline De 20.001 a 50.000 habitantes & 34 & 1.011 .301 \\
\hline De 50.001 a 100.000 habitantes & 15 & 943.957 \\
\hline De 100.001 a 500.000 habitantes & 11 & 2.150 .042 \\
\hline Acima de 500.000 habitantes & 1 & 515.288 \\
\hline Total & 293 & 6.248 .436 \\
\hline
\end{tabular}

Fonte: Elaborado a partir dos dados do Censo Demográfico 2010 (IBGE, 2010).

A quantidade de municípios por classe populacional mostra que a configuração de Santa Catarina é a de um Estado formado por pequenos e micromunicípios. Verifica-se na tabela 1 que os micromunicípios (população total de até 5.000 habitantes) representam 37\% do total. Apenas 27 municípios possuem acima de 50.000 habitantes e somente 1, Joinville, conta com mais de 500.000 habitantes, sendo que Joinville não é a capital do Estado. São 12 municípios com mais de 100 mil habitantes, respondendo por $43 \%$ da população estadual: Balneário Camboriú, Blumenau, Brusque, Chapecó, Criciúma, Florianópolis, Itajaí, Jaraguá do Sul, Joinville, Lages, Palhoça e São José.

Os dados catarinenses corroboram as pesquisas de Allebrandt (2002) e Joffre Neto (2003), que evidenciaram o Brasil como um país de pequenos municípios. Santa Catarina talvez seja um Estado ainda mais peculiar, haja vista que possui aproximadamente 79,1\% dos municípios com até 20.000 habitantes, enquanto a média nacional é de $73 \%$.

O Estado de Santa Catarina não apresenta grandes concentrações populacionais. A população 
encontra-se distribuída uniformemente, sendo as cidades majoritariamente de pequeno e médio tamanho. Até mesmo a cidade de Florianópolis distingue-se das outras capitais brasileiras por não apresentar grande concentração populacional, o que confere ao Estado uma singularidade.

Considerando o objeto de estudo, foi necessário identificar as Câmaras Municipais de Santa Catarina com portal eletrônico. Na consulta realizada no portal do Governo do Estado de Santa Catarina, em 19 de janeiro de 2010, foram identificadas 37 câmaras municipais com portal eletrônico. Em uma segunda etapa de consultas, realizadas no site Google, nos dias 20 e 21 de janeiro de 2010, foram identificadas outras 56 câmaras municipais com portal eletrônico. Outras buscas foram feitas nos portais de Associações dos Municípios Catarinenses e no portal do programa Interlegis do Senado Federal, porém, não foram verificadas outras câmaras municipais com portal eletrônico, além daquelas já identificadas. Conforme levantamento realizado, em 93 municípios catarinenses há a disponibilização de portais eletrônicos pelos legislativos locais. A quantidade destes municípios por grupo populacional é apresentada na tabela 2.

Tabela 2 - Distribuição das Câmaras Municipais com portal eletrônico por classe populacional

\begin{tabular}{|l|c|c|r|}
\hline \multicolumn{1}{|c|}{ Classe Populacional } & Quantidade de municípios & $\begin{array}{c}\text { Quantidade de Câmaras } \\
\text { com portal eletrônico }\end{array}$ & $\%$ \\
\hline Até 5.000 habitantes & 108 & 9 & $8,33 \%$ \\
\hline De 5.001 a 10.000 habitantes & 64 & 8 & $12,50 \%$ \\
\hline De 10.001 a 20.000 habitantes & 60 & 22 & $36,67 \%$ \\
\hline De 20.001 a 50.000 habitantes & 34 & 29 & $85,29 \%$ \\
\hline De 50.001 a 100.000 habitantes & 15 & 13 & $86,67 \%$ \\
\hline De 100.001 a 500.000 habitantes & 11 & 11 & $100,00 \%$ \\
\hline Acima de 500.000 habitantes & 1 & 93 & $100,00 \%$ \\
\hline Total & 293 & & $31,74 \%$ \\
\hline
\end{tabular}

Fonte: Dados da pesquisa.

A tabela 2 evidencia que apenas 31,74\% das Câmaras Municipais de Santa Catarina possuem portal eletrônico. $\mathrm{Na}$ análise por classes populacionais, observa-se que o percentual de Câmaras com portal eletrônico, em relação à quantidade de municípios, cresce à medida que se avança nas classes. Nos municípios com população superior a 50.000 habitantes, que são em número de 27 , somente 2 câmaras não disponibilizam portal.

Considerando que 92,59\% dos municípios com população superior a 50.000 habitantes contam com a disponibilização de portais pelos legislativos, e que isso ocorre em $25,56 \%$ dos municípios com população inferior a 50.000 habitantes, acredita-se que o tamanho populacional pode influenciar a presença ou não do portal eletrônico no legislativo local. Parte-se do pressuposto de que o tamanho populacional pode influenciar também a estruturação dos portais do ponto de vista da accountability. Havia uma expectativa de que, à medida que a população crescesse, aumentariam as condições de maiores recursos tecnológicos, financeiros e recursos humanos para construir os portais.

Identificadas as câmaras municipais catarinenses com portal eletrônico, utilizou-se o modelo de análise com guia na observação dos portais e anotação das informações consideradas relevantes. As consultas aos portais para verificar a construção de condições de prestação de contas, de transparência e de participação foram realizadas no mês de dezembro de 2010 e nos meses janeiro e fevereiro de 2011.

As análises das observações nos portais eletrônicos foram organizadas por classes populacionais, utilizando as classes de tamanho da população dos municípios brasileiros, definidas pelo Instituto Brasileiro de Geografia e Estatística (IBGE, 2007), já evidenciadas nas tabelas 1 e 2 . Na análise por classes populacionais, percebeu-se que municípios com 
maior população não necessariamente apresentam portais dos legislativos com maiores condições de construção de prestação de contas, de transparência e de participação. Em geral, não foram observados indicadores mais avançados nos portais de municípios maiores, conforme síntese evidenciada na tabela 3.

Tabela 3 - Accountability/Síntese das dimensões analisadas

\begin{tabular}{|c|c|c|c|c|c|c|c|c|c|c|c|c|}
\hline \multirow[b]{2}{*}{ Classe Populacional } & \multicolumn{4}{|c|}{ Prestação de Contas } & \multicolumn{4}{|c|}{ Transparência } & \multicolumn{4}{|c|}{ Participação } \\
\hline & $\frac{\pi}{\vec{z}}$ & 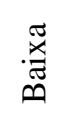 & 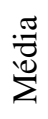 & $\frac{\pi}{\stackrel{*}{*}}$ & $\frac{\pi}{z}$ & 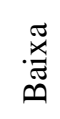 & 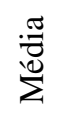 & 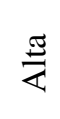 & $\frac{\pi}{z}$ & 芉 & 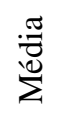 & $\stackrel{\Xi}{\stackrel{\Xi}{*}}$ \\
\hline Até 5.000 habitantes & 7 & 2 & 0 & 0 & 1 & 1 & 5 & 2 & 1 & 7 & 1 & 0 \\
\hline De 5.001 a 10.000 habitantes & 3 & 4 & 1 & 0 & 1 & 1 & 6 & 0 & 1 & 7 & 0 & 0 \\
\hline De 10.001 a 20.000 habitantes & 19 & 3 & 0 & 0 & 0 & 14 & 3 & 5 & 1 & 12 & 8 & 1 \\
\hline De 20.001 a 50.000 habitantes & 14 & 13 & 0 & 2 & 0 & 22 & 2 & 5 & 1 & 18 & 8 & 2 \\
\hline De 50.001 a 100.000 habitantes & 7 & 5 & 0 & 1 & 0 & 10 & 0 & 3 & 0 & 7 & 3 & 3 \\
\hline De 100.001 a 500.000 habitantes & 0 & 8 & 0 & 4 & 0 & 6 & 0 & 6 & 0 & 5 & 1 & 6 \\
\hline Total & 50 & 35 & 1 & 7 & 2 & 54 & 16 & 21 & 4 & 56 & 21 & 12 \\
\hline
\end{tabular}

Fonte: Raupp e Pinho (2012).

A partir da síntese das dimensões analisadas, elaborou-se um ranking dos portais eletrônicos das câmaras municipais de Santa Catarina em termos de accountability, apresentado na figura 2 .

\begin{tabular}{|c|c|c|c|c|}
\hline 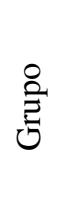 & Câmara Municipal & 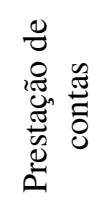 & 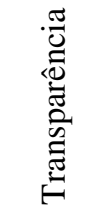 & 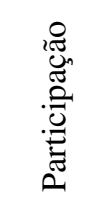 \\
\hline 1 & Criciúma, Florianópolis, Joinville & Alta & alta & alta \\
\hline 2 & Canoinhas, Chapecó, São José, & baixa & alta & alta \\
\hline 2 & Rio do Sul, Timbó & Alta & alta & baixa \\
\hline 3 & Xanxerê & nula & alta & alta \\
\hline 4 & Capinzal & Alta & baixa & média \\
\hline 4 & Concórdia, Papanduva & baixa & alta & média \\
\hline 5 & Dionísio Cerqueira, Itaiópolis, Taió & nula & alta & média \\
\hline 6 & Balneário Camboriú, Porto União & baixa & alta & baixa \\
\hline 6 & Jaraguá do Sul, Laguna & Alta & baixa & baixa \\
\hline 6 & Palhoça, São Miguel do Oeste & baixa & baixa & alta \\
\hline 7 & Caçador, Indaial, Pinhalzinho & nula & baixa & alta \\
\hline 7 & Campos Novos, Imaruí, Jupiá, Turvo & nula & alta & baixa \\
\hline 8 & Novo Horizonte & nula & alta & nula \\
\hline 9 & Agronômica, Barra Velha & baixa & média & média \\
\hline 9 & Irani & média & média & baixa \\
\hline 10 & Morro da Fumaça & nula & média & média \\
\hline 11 & Água Doce, Anchieta, Urussanga & baixa & média & baixa \\
\hline 11 & Gaspar, Itajaí, Itapema, Massaranduba & baixa & baixa & média \\
\hline 12 & $\begin{array}{l}\text { Biguaçu, Imbituba, Lebon Régis, Maravilha, Palmitos, Schoroeder, } \\
\text { Tijucas, Xaxim }\end{array}$ & nula & baixa & média \\
\hline 12 & $\begin{array}{l}\text { Ermo, Galvão, Iomerê, Passo de Torres, Pouso Redondo, São Bernardino, } \\
\text { Trombudo Central }\end{array}$ & nula & média & baixa \\
\hline 13 & Garopaba, Rio do Oeste & nula & média & nula \\
\hline 14 & Blumenau, Braço do Norte, Brusque, Capivari de Baixo, Grão-Pará, Içara, & baixa & baixa & baixa \\
\hline
\end{tabular}




\begin{tabular}{|c|l|c|c|c|}
\hline & $\begin{array}{l}\text { Itapoá, Joaçaba, Lages, Orleans, Penha, Rio Negrinho, São Martinho, } \\
\text { Videira }\end{array}$ & & & \\
\hline 15 & $\begin{array}{l}\text { Araquari, Balneário de Piçarras, Bombinhas, Camboriú, Campo Alegre, } \\
\text { Corupá, Faxinal de Guedes, Fraiburgo, Guaramirim, Ituporanga, Mafra, } \\
\text { Nova Veneza, Pomerode, São Bento do Sul, São Francisco do Sul, Seara, } \\
\text { Siderópolis, Sombrio, Tubarão }\end{array}$ & nula & baixa & baixa \\
\hline 15 & São Lourenço do Oeste & baixa & baixa & nula \\
\hline 15 & Bom Retiro & nula & nula & baixa \\
\hline 15 & Lacerdópolis & nula & baixa \\
\hline
\end{tabular}

Figura 2 - Ranking dos portais de câmaras municipais

Fonte: Dados da pesquisa.

A proposição do ranking dos portais de câmaras municipais em termos de accountability está baseada no grau decrescente de condições de construção das três dimensões analisadas: prestação de contas, transparência e participação. Por exemplo, os portais que apresentaram alta capacidade nas três dimensões ocupam a primeira posição. Para as próximas posições do ranking consideramos a seguinte ordem de prioridade: quantidade de dimensões com alta capacidade; quantidade de dimensões com média capacidade; quantidade de dimensões com baixa capacidade; e, por último, quantidade de dimensões com nula capacidade.

A figura 2, que decorre dos resultados da pesquisa empírica, mostra, com pouquíssimas exceções (Criciúma, Florianópolis, Joinville, Canoinhas, Chapecó, Rio do Sul, São José, Timbó e Xanxerê), evidências de que os portais eletrônicos não são utilizados como tecnologia de promoção da accountability. Mesmo assim, vale notar que fora as 3 primeiras câmaras, as demais, mesmo atingindo 2 capacidades alta, ainda convivem com uma capacidade negativa (nula ou baixa). Os casos considerados críticos, do ponto de vista da construção da accountability, estão no grupo 15.

Os achados corroboram com Cruz, Silva e Santos (2009) ao afirmarem que, embora haja recomendação no texto legal, as informações concernentes ao planejamento, execução e prestação de contas do orçamento das diversas esferas governamentais não são disponibilizadas com uniformidade na rede mundial de computadores, de modo que se podem observar portais com uma significativa quantidade de relatórios e outras informações e outros com reduzida evidenciação (CRUZ, SILVA, SANTOS, 2009).

O ranking também encontra respaldo em Cunha e Santos (2005) que investigaram o uso de meios eletrônicos por vereadores brasileiros na comunicação com o cidadão, de municípios brasileiros com mais de quinhentos mil habitantes. Concluíram os autores que os parlamentares possuem endereço de correio eletrônico, mas não respondem as mensagens que a eles são enviadas. Os seus sítios mostram diferenças substanciais em conteúdo e qualidade. De um lado, os "santinhos eletrônicos", sem nenhum mecanismo de interatividade e se imitando à biografia política do vereador. No outro extremo, sítios que são um repositório da atuação do vereador e podem ser usados na interação com o cidadão, apresentando múltiplos artefatos de interatividade, com conteúdo recente e atualizado (CUNHA, SANTOS, 2005). Outra explicação para esse contexto, segundo Pinho (2011), é que, apesar de a participação política possibilitada pelas TICs ser considerada como uma das promessas da internet, os resultados têm sido muito modestos, pois a participação precisa ser entendida no contexto da contemporaneidade, onde se tem detectado um abandono ou desvalorização da política (PINHO, 2011).

Parece, no entanto, necessário recorrer a outros ângulos para entender mais profundamente a temática em tela. Assim, a questão colocada por Teixeira (2004), de que o fato de o vereador, geralmente, ter uma maior concentração de votos num distrito onde ele provavelmente reside, aproxima-o ainda mais do seu eleitorado e coloca-o frente a necessidade de responder com maior rapidez e eficiência, as demandas apresentadas pelos seus eleitores, contribuindo para a

R. Cont. Ufba, Salvador-Ba, v. 7, n. 1, p. 69-83, Janeiro-abril 2013 
dispensa de meios digitais por parte do vereador, já que ele se encontra com o eleitor/cidadão no bar, na venda, na praça, na Igreja, para não mencionar o fato de os eleitores/cidadãos não terem acesso digital. Esse raciocínio/argumento é válido para aquelas cidades pequenas do interior, já não se observando em cidades médias e grandes, pois mesmo vivendo no mesmo bairro, as relações já são mais anônimas, impessoais. Este tipo de consideração redefine os limites e alcances do que se entende por sociedade digital. Em municípios menores, esta não chegou, não por limitações tecnológicas, mas sim, porque não se faria necessária.

O ranking construído mostra que, de maneira geral, há uma ausência de construção de accountability, visto que os portais eletrônicos de Câmaras Municipais do Estado de Santa Catarina são, atualmente, instrumentos com nula ou baixa capacidade, servindo, na sua maioria, como murais eletrônicos. É como se governos, conforme Pinho (2008), ainda tivessem condições de incorporar toda uma nova cultura de utilização das TICs, ou seja, não estariam devidamente preparados para esse novo período, e isso, talvez, esteja ainda em construção.

\section{Conclusões}

$\mathrm{O}$ artigo teve por objetivo propor um ranking dos legislativos locais em termos de construção da accountability a partir da análise de 93 portais eletrônicos de câmaras municipais do Estado de Santa Catarina. Os dados coletados a partir do modelo de análise proposto por Raupp e Pinho (2012) possibilitaram a proposição do ranking que foi estruturado com base no grau decrescente de condições das três dimensões da accountability analisadas: prestação de contas, transparência e participação.

$\mathrm{Na}$ análise individual das dimensões, percebemos que a maioria dos portais apresenta capacidade nula ou baixa em possibilitar a construção de prestação de contas. As câmaras não utilizam os portais para prestar contas dos gastos incorridos, nem mesmo a legislação é cumprida (BRASIL 2000, BRASIL 2009, BRASIL, 2011). Sem o atendimento do mínimo, que é a exigência legal, estamos distantes de verificar, na prática, uma perspectiva ampliada de prestação de contas (PRADO, 2004).

As condições de transparência das ações parlamentares parecem mais ativas comparadas à dimensão prestação de contas, mesmo tendo uma predominância de portais com indicadores de baixa capacidade de transparência. Em outra perspectiva, pode-se destacar que a ocorrência mínima de portais com nula capacidade somada às condições de alta capacidade observadas, pode indicar que se está diante de um processo em construção, com possibilidades de se apresentar, em um futuro próximo, mais aperfeiçoado. De qualquer forma, considerando as atuais condições, não há, de uma maneira geral, construção de accountability por meio da transparência.

No que concerne à participação, a maioria dos indicadores observados nos portais concentrase no extrato baixa capacidade. Cabe ressaltar que não foi objeto de estudo observar se a participação realmente ocorre. O modelo de análise permite identificar se os instrumentos de participação existem, mas não permite inferir se a participação acontece. Neste caso, a tecnologia existe, mas não é utilizada para disponibilizar instrumentos de interação entre o cidadão e o ente governamental.

Mesmo Laia et al. (2011) concluindo que o desenho institucional do governo eletrônico brasileiro limita a utilização das TICs na prestação de serviços públicos integrados, na ampliação de participação e transparência, e no aprimoramento de políticas públicas, o contexto dos portais eletrônicos de câmaras municipais catarinenses parece ainda mais limitado. A elaboração do ranking mostra o mapa atual das condições de accountability nos 
portais eletrônicos observados, distantes de serem atendidas, dadas as características de prestação de contas, transparência e participação verificadas.

\section{Referências}

AGOSTINETO, Raquel Crestani; RAUPP, Fabiano Maury. Prestação de contas por meio de portais eletrônicos: um estudo em câmaras municipais da grande Florianópolis. Revista Universo Contábil, Blumenau, v.6, n. 3, p. 64-79, jul/set. 2010.

ALLEBRANDT, S. L. A participação da sociedade na gestão pública local e na produção das políticas públicas: a atuação dos conselhos municipais. Ijuí: Ed. UNIJUÍ, 2002.

BORGES, Jussara ; SILVA, Helena Pereira.Democracia eletrônica e competência informacional.Informação\& Sociedade: Estudos, João Pessoa, v.16, n.1, p. 168-178, jan/jun. 2006.

BRASIL. Lei de Responsabilidade Fiscal. Lei Complementar $n^{\circ} 101$, de 04 de Maio de 2000. Presidência da República. Casa Civil. Subchefia para Assuntos Jurídicos. Brasília, 2000.

BRASIL. Lei da Transparência. Lei Complementar n 131, de 27 de Maio de 2009. Presidência da República. Casa Civil. Subchefia para Assuntos Jurídicos. Brasília, 2009.

BRASIL. Lei de Acesso a Informações Públicas. Lei n 12.527, de 18de novembro de 2011. Presidência da República. Casa Civil. Subchefia para Assuntos Jurídicos. Brasília, 2011.

CARDOSO, Renê Fernando. Um estudo sobre os resultados da utilização da bolsa eletrônica de compras no governo do Estado de São Paulo. Revista do Serviço Público, ano 55, n. 4, p. 31-44, out./dez. 2004.

CRESWELL, J. W. Projeto de pesquisa: método qualitativo, quantitativo e misto. Porto Alegre: Artmed, 2007.

CRUZ, Claudia Ferreira da; FERREIRA, Aracéli Cristina de Sousa; SILVA, Lino Martins da.Tendências teóricas nos estudos com abordagem na divulgação e transparência de informações sobre gestão pública. In: ENCONTRO DE ADMINISTRAÇÃO DA INFORMAÇÃO, 3., 2009, Porto Alegre. Anais... Rio de Janeiro: ANPAD, 2009.

CRUZ, Cláudia Ferreira; SILVA, Lino Martins; SANTOS, Ruthberg. Transparência da gestão fiscal: um estudo a partir dos portais eletrônicos dos maiores municípios do estado do Rio de Janeiro.Contabilidade, Gestão e Governança, Brasília, v.12, n. 3, p. 102-115, set/dez. 2009.

CUNHA, Maria Alexandra Viegas Cortez da; SANTOS, Ghabryelle Schwarzbach dos. O uso dos meios eletrônicos no relacionamento do parlamentar com o cidadão nos municípios brasileiros. Revista Organizações \& Sociedade, Salvador, v.12, n. 35, p. 1-21, out/dez 2005.

DINIZ, Eduardo Henrique; BARBOSA, Alexandre Fernandes; JUNQUEIRA, Alvaro Ribeiro Botelho; PRADO, Otavio.O governo eletrônico no Brasil: perspectiva histórica a partir de um 
modelo estruturado de análise. Revista Administração Pública, Rio de Janeiro,v.43, n.1, p. 23-48, jan/fev. 2009.

FREIRE, André Pimenta, CASTRO; Mário de; FORTES, Renata Pontin de Mattos. Acessibilidade dos sítios web dos governos estaduais brasileiros: uma análise quantitativa entre 1996 e 2007. Revista Administração Pública, Rio de Janeiro,v.43, n. 2, p.395-414, mar/abr. 2009.

GOMES FILHO, Adhemar Bento. O desafio de implementar uma gestão pública transparente. In: CONGRESO INTERNACIONAL DEL CLAD SOBRE LA REFORMA DEL ESTADO Y DE LA ADMINISTRACIÓN PÚBLICA, 10., 2005, Santiago. Anais...Santiago: CLAD, 2005.

INSTITUTO BRASILEIRO DE GEOGRÁFIA E ESTATÍSTICA - IBGE. Contagem da população 2007. 2007. Disponível em: <http://www.ibge.gov.br/>. Acesso em: 25 set. 2012.

INSTITUTO BRASILEIRO DE GEOGRÁFIA E ESTATÍSTICA - IBGE. Censo demográfico 2010. 2010. Disponível em: <http://www.ibge.gov.br/>. Acesso em: 15 ago. 2012 .

JOFFRE NETO, J. M. Câmaras municipais no Brasil: ascensão e declínio. São Paulo: EAESP-FGV, 2003.

LAIA, Marconi Martins de; CUNHA, Maria Alexandre; NOGUEIRA, Antônio Roberto Ramos; MAZZON, José Afonso. Políticas de governo eletrônico no Brasil: contexto, gestão de tic e resultados. Revista de Administração de Empresas Eletrônica, São Paulo, v.51, n. 1, p. 43-57,jan-fev. 2011.

MEDEIROS, Paulo Henrique Ramos; GUIMARÃES, Tomás de Aquino. A institucionalização do governo eletrônico no Brasil. Revistas de Administração de Empresas Eletrônica, São Paulo, v. 46, n. 4, p. 1-13,out/dez. 2006.

PINHO, José Antonio Gomes de. Investigando portais de governo eletrônico de estados no Brasil: muita tecnologia, pouca democracia. Revista Administração Pública, Rio de Janeiro, v.42, n. 3, p. 471-493, maio/jun. 2008.

PINHO, José Antonio Gomes de. Sociedade da informação, capitalismo e sociedade civil: reflexões sobre política, internet e democracia na realidade brasileira. Revista de Administração de Empresas, São Paulo, v.51,n. 1, p. 98-106, jan-fev. 2011.

PINHO, J. A. G.; SACRAMENTO, A. R. Accountability: já podemos traduzi-la para o português? Revista de Administração Pública, v. 43, n. 6, p.1343-1368, nov./dez. 2009.

PLATT NETO, Orion Augusto; CRUZ, Flávio da; ENSSLIN, Sandra Rolim, ENSSLIN, Leonardo. Publicidade e transparência das contas públicas: obrigatoriedade e abrangência destes princípios na administração pública brasileira. Revista Contabilidade Vista \& Revista, Belo Horizonte, v. 18, n. 1, p. 75-94, jan./mar. 2007.

PRADO, O. Governo eletrônico e transparência: a publicização das contas públicas 
das capitais brasileiras. 2004. 180 p. Dissertação (Mestrado em Administração de Empresas) — Escola de Administração de Empresas de São Paulo da Fundação Getulio Vargas, SãoPaulo, 2004.

PRADO, Otávio; LOUREIRO, Maria Rita Garcia. Governo eletrônico e transparência: avaliação da publicização das contas públicas das capitais brasileiras. Revista Alcance, Itajaí, v.13, n. 3, p. 355-372, set/dez 2006.

RAUPP, Fabiano Maury; PINHO, José Antonio Gomes de. Construindo a accountability em portais eletrônicos de câmaras municipais: um estudo de caso em Santa Catarina. Cadernos EBAPE.BR, Rio de Janeiro, v.9, n. 1, p. 116-138, mar. 2011.

RAUPP, Fabiano Maury; PINHO, José Antonio Gomes de Pinho. Accountability em câmaras municipais: uma investigação em portais eletrônicos. In: SIMPÓSIO DE ADMINISTRAÇÃO DA PRODUÇÃO, LOGÍSTICA E OPERAÇÕES INTERNACIONAIS, 15., 2012, Rio de Janeiro. Anais...São Paulo: FGV-EAESP, 2012.

REZENDE, Denis Alcides. Planejamento de informações públicas municipais: sistemas de informação e de conhecimento, informática e governo eletrônico integrados aos planejamentos das prefeituras e municípios. Revista Administração Pública, Rio de Janeiro, v.41, n. 3, p. 505-536, maio/jun. 2007.

RUEDIGER, Marco Aurélio. Governo eletrônico e democracia: uma análise preliminar dos impactos e potencialidades na gestão pública. Revista Organizações \& Sociedade, Salvador, v.9, n. 25, p. 1-15, set/dez 2002.

SANTOS,José Carlos Sales; SILVA, Rubens Ribeiro Gonçalves. Governo eletrônico e participação política nos websites dos deputados da assembléia legislativa do estado da Bahia. Informação\& Sociedade: Estudos, João Pessoa, v.21, n.1, p. 215-224, jan./abr. 2011.

TEIXEIRA, E. C. As dimensões da participação cidadã. Caderno CRH, Salvador, n. 26/27, p. 179-209, jan./dez. 1997.

TEIXEIRA, M. A. C. Negociação política e as formas de interação executivo legislativo no Brasil no período de 1983 a 1992. Cadernos Gestão Pública e Cidadania, São Paulo, v. 9, n. 40, jul. 2004.

ZURRA, R. J. O.; CARVALHO, M. A. O E-Legislativo como ferramenta de transparência na administração pública brasileira.In: ENCONTRO DE ADMINISTRAÇÃO PÚBLICA E GOVERNANÇA, III, 2008, Salvador. Anais... Rio de Janeiro: ANPAD, 2008. 